\title{
Study on advance care planning in care dependent community-dwelling older persons in Germany (STADPLAN): protocol of a cluster-randomised controlled trial
}

Rieke Schnakenberg ${ }^{1 *}$, Katharina Silies ${ }^{2}$, Almuth Berg $^{3}$, Änne Kirchner $^{3}$, Henriette Langner $^{3}$, Yuliya Chuvayaran $^{4}$, Juliane Köberlein-Neu ${ }^{4}$, Burkhard Haastert ${ }^{5}$, Birgitt Wiese ${ }^{6}$, Gabriele Meyer ${ }^{3}$, Sascha Köpke ${ }^{2}$ and Falk Hoffmann ${ }^{1}$

\begin{abstract}
Background: In Germany, advance care planning (ACP) was first introduced by law in 2015. However, ACP is still uncommon in Germany and only few people have advance directive forms. This study aims to evaluate an ACP program in care dependent community-dwelling persons, compared to optimised usual care.

Methods: A cluster-randomised controlled trial of 12 months duration will be conducted in 3 German study sites comparing the pretested ACP-counselling offered by trained nurses with a control group receiving optimised usual care. Using external concealed randomisation, 16 home care services each will be included in the intervention and the control group (30 participants per cluster; $n=960$ ). Eligibility criteria for patients are: $\geq 60$ years, somehow care dependent, adequate German language skills, assumed life-expectancy of $\geq 4$ weeks, and cognitive ability for participation.

ACP will be delivered by trained nurse facilitators of the respective home care services and communication will include proxy decision-makers. The primary endpoint will be patient activation, assessed by the Patient Activation Measure (PAM-13). Secondary endpoints include ACP-engagement, proportion of prepared advance directives, number and duration of hospitalisations, quality of life as well as depression and anxiety. Further, comprehensive economic and process evaluations will be conducted.
\end{abstract}

Discussion: STADPLAN is the first study in Germany that assesses an adapted ACP intervention with trained nurses in home care services and the first international study focusing on cost effectiveness of ACP in community-dwelling older persons. The results will help to improve the understanding and communicating of patients' preferences regarding medical treatment and care and thereby contribute to patients' autonomy.

Trial registration: German Clinical Trials Register: DRKS00016886 (Date of registration: 04.06.2019).

Keywords: Advance care planning, Study protocol, Home care setting, Cluster-RCT

\footnotetext{
* Correspondence: rieke.schnakenberg@uol.de

${ }^{1}$ Department of Health Services Research, Faculty of Medicine and Health Sciences, Carl von Ossietzky University Oldenburg, Oldenburg, Germany

Full list of author information is available at the end of the article
}

(c) The Author(s). 2020 Open Access This article is licensed under a Creative Commons Attribution 4.0 International License, which permits use, sharing, adaptation, distribution and reproduction in any medium or format, as long as you give appropriate credit to the original author(s) and the source, provide a link to the Creative Commons licence, and indicate if changes were made. The images or other third party material in this article are included in the article's Creative Commons licence, unless indicated otherwise in a credit line to the material. If material is not included in the article's Creative Commons licence and your intended use is not permitted by statutory regulation or exceeds the permitted use, you will need to obtain permission directly from the copyright holder. To view a copy of this licence, visit http://creativecommons.org/licenses/by/4.0/. The Creative Commons Public Domain Dedication waiver (http://creativecommons.org/publicdomain/zero/1.0/) applies to the data made available in this article, unless otherwise stated in a credit line to the data. 


\section{BACKGOUND}

Worldwide demographic changes lead to increased numbers of care dependent and chronically ill older persons $[1,2]$. Functional and cognitive impairment are often accompanied by multimorbidity as well as nursing home admissions and frequent hospital stays [3-5]. Furthermore, care dependency decreases life expectancy [6]. For Germany, the number of care dependent persons is estimated to rise from 3.4 million today [7] to over 4.5 million in 2050 [8], of whom most will be communitydwellers [9].

Shared decision making with respect to nursing and medical decisions as well as improved communication processes between patients and health care professionals are essential elements of high-quality care [10]. In Germany, shared decision making has been included in the Patients' Rights Act "Patientenrechtegesetz" since 2013.

Therefore, the concept of advance care planning (ACP) has become increasingly important. ACP is a process of discussing in advance a person's health care preferences and wishes regarding future treatment especially if - due to physical or mental deterioration the person cannot state his or her wishes anymore [11]. The communication process takes place between individuals and specifically skilled facilitators such as nurses, social workers, or physicians and may also involve relatives.

Persons are encouraged to document their future treatment preferences in advance directives (AD) and update them regularly as health status and preferences might change over time. By these repeated conversations, health care professionals and relatives learn about a person's priorities, beliefs, values, and choices and therefore are able to arrange treatment accordingly in potential future situations [11]. In this way, ACP extends a persons' autonomy to a phase in life where he or she becomes incapacitated.

Although the German Advance Directives Act "Patientenverfügungsgesetz" of 2009 confirmed that ADs are binding and the prevalence has been rising during the last years, ACP is still not widely implemented in Germany [12]. Since 2015, the Act to improve Hospice and Palliative Care ("Hospiz- und Palliativgesetz") stipulates that ACP in German nursing homes is funded by the health insurance funds. However, only few residents, have an $\mathrm{AD}$ and most fail to accurately state what should be done when the person acutely becomes incapable of participating in treatment decisions [13, 14]. A patient's AD may also be disregarded by medical and nursing staff due to insufficient communication.

Therefore, successful ACP programs require a crosssectoral, multidisciplinary approach, which implies improved communication even among all healthcare providers [15]. Studies from other countries have shown that ACP can reduce distress, depression and anxiety not only in residents but also in significant others and care staff [16, 17]. However, compared to optimised usual care, ACP programs have not been studied solely in community-dwellers $[18,19]$. Therefore, no evidence is currently available on the effectiveness of ACP programs implemented by trained nurse facilitators in the home care setting. The cost-effectiveness of ACP is not well understood, although some evidence indicates that ACP is associated with healthcare savings in nursing home residents [20-22].

\section{Objective}

The main focus of this study is to evaluate the effect of an ACP program on patients' activation regarding healthcare issues, compared to optimised usual care in care dependent community-dwelling older persons.

Further aims are to assess the intervention's impact on patients' ACP engagement as well as prepared AD forms, hospitalisations and institutionalisations, anxiety and depression, self-reported health-related quality of life, and mortality. A process evaluation developed according to the MRC framework [23] will be performed to analyse the implementation process, mechanisms of impact and contextual factors that might influence the outcome of the intervention. A health economic evaluation will assess the cost implications of the intervention over 12-months of follow-up.

\section{Methods}

\section{Study design and setting}

STADPLAN (STudy on ADvance care PLANning in care dependent community dwelling older persons) is a twoarm cluster randomised controlled trial of 12-months follow-up, conducted to evaluate the effect of an ACP program compared to optimised usual care for people living at home receiving professional home care. Figure 1 summarises the process of enrolment, randomisation, and measurement points during follow-up.

\section{Preparatory work}

The patient-centred ACP programme "Respecting Choices" $^{\oplus}$ [24] was adapted to the home care setting and the German context (GM, AB, HL, ÄK). The intervention components were systematically adapted to the needs of community nursing care in Germany and guided by the Behaviour Change Wheel method [25]. Compared to the "Respecting Choices" program, the adapted version is less time consuming and more feasible for nurses who will deliver the ACP counselling under "real-life" conditions. The aim is not only to prove effectiveness, but also feasibility and potential for future 


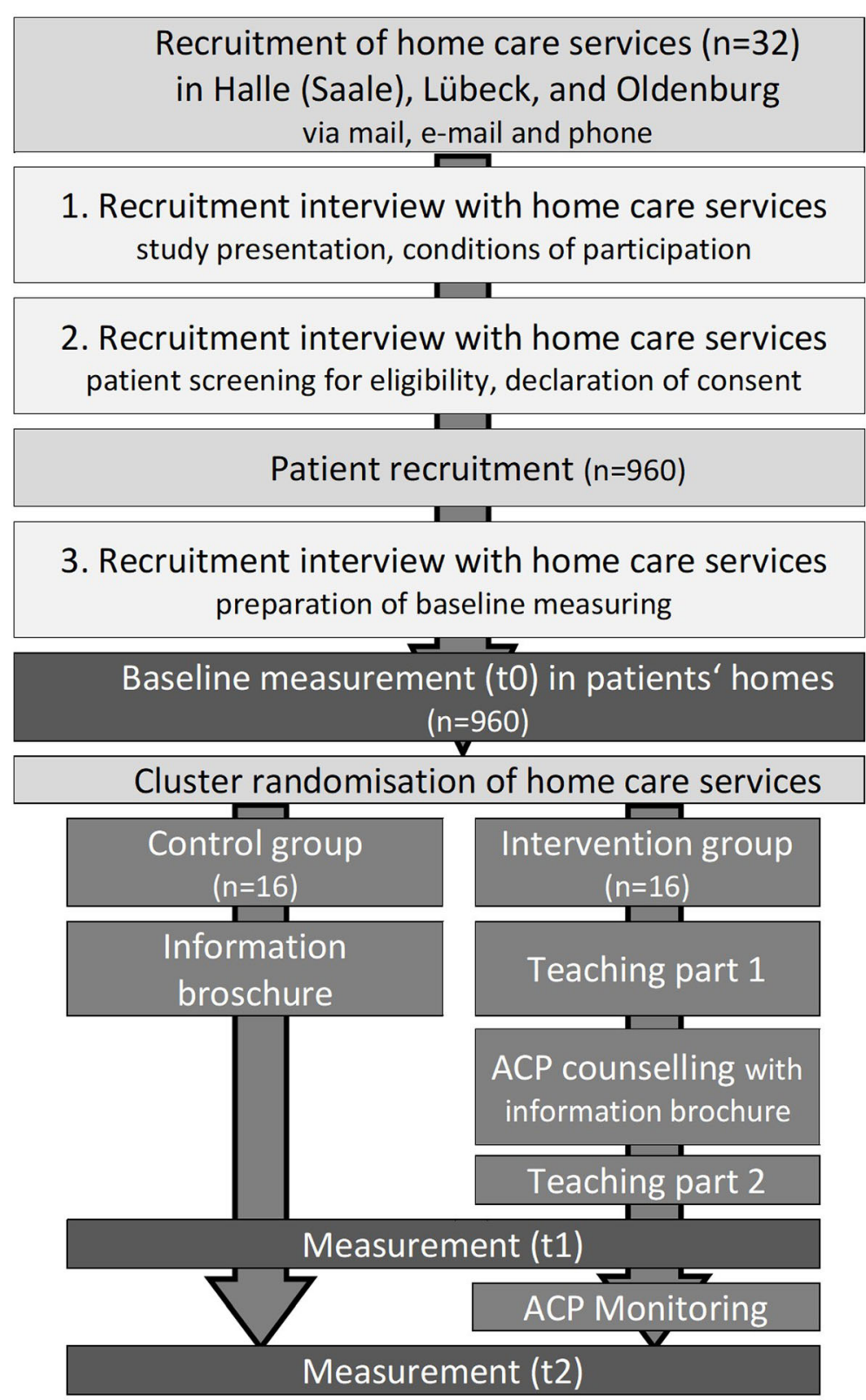

Fig. 1 Study flow chart

implementation within existing structures rather than setting up parallel new structures.

The adapted intervention of the STADPLAN study was piloted with four home care services (two each in Halle (Saale) and Oldenburg) in 2018. The pilot study included the whole intervention, the recruitment of home care services and patients, baseline measurements, and parts of the process evaluation up to 3 months after baseline measurement. It helped to optimise the feasibility regarding recruitment, as one result was to minimize the time required for participation. One result was, that the acceptability could be raised by means of decreasing the age from 65 to 60 as inclusion criterion, because the nursing services stated to find it relevant not to exclude the younger clients from information regarding ACP. Moreover, it was helpful to maximise the understanding of used forms like written information and the conversation guide as well as the acceptability of the intervention parts and organisational factors by getting direct feedback from the nurses.

In- and exclusion criteria for home care services

In total, 32 home care services will be recruited throughout the catchment areas of the three study sites Lübeck, 
Oldenburg (both north western Germany) and Halle (Saale) (eastern Germany). Each home care service has to care for 70 patients or more and be willing to assign at least two key nurses for the ACP training as well as for the counselling conversations. Minimum qualification of the participating nurses is 3 year professional education (registered nurse) or a bachelor's degree. Key nurses recruit participating patients and in the intervention group conduct the ACP counselling additionally. Home care services with mainly or solely special alignment, e.g. palliative, paediatric or intensive care will not be considered.

\section{In- and exclusion criteria for patients}

To be eligible, patients have to be (i) clients of a participating home care service, (ii) aged 60 years or older, (iii) assigned to a care grade of 1 or higher, and (iv) rated into a life-expectancy of at least 4 weeks. Furthermore, (v) adequate German language skills, and (vi) the cognitive ability to follow the intervention and data collection are required. The latter will be assessed using the stepwise approach of the Dementia Screening Scale (DSS), a validated seven-item proxy instrument for nurses where a score of " 0 " indicates no cognitive impairment and "14" the most severe cognitive impairment [26]. Patients with a total DSS score $<3$ will be included in the study whereas those scoring between 3 and 5 will only be eligible if the respective key nurses consider them competent to follow the intervention and to give informed consent. No further exclusion criteria will be applied.

An expected mean of 30 patients are aimed to be included per home care service ( $n=960$ patients).

\section{Recruitment}

A total of 288 home care services are located in the three study sites Oldenburg, Lübeck and Halle (Saale) [27]. Of those $32(11 \%)$ will be recruited. The selected home care services will be invited to take part in the study via postal mail and subsequent telephone calls. This strategy has been successfully applied in previous studies conducted in nursing homes $[28,29]$ or home care services [30]. The recruitment process will be documented including dates, contact times, and feedback.

Interested home care services have to take part in three separate recruitment interviews provided by study assistants, following the structure presented in Fig. 1 and involving the key nurses, who will thereby be prepared for the standardised patient recruitment. Key nurses will prepare a list of all patients fulfilling the inclusion criteria. This list will be ordered randomly and subsequent patients will be asked for participation until 30 patients will be recruited.

\section{Randomisation}

Randomisation will be carried out on the cluster level (i.e. the home care service) by one investigator (JKN), who is not involved in the recruitment process. Thus, allocation concealment will be guaranteed. Clusters will be allocated 1:1 between intervention and control group. Computer-generated lists will be used with block sizes of two in order to inform the home care services as fast as possible so they can reliably plan time for intervention. Each pair will be allocated simultaneously. Randomisation will be stratified by study site (Oldenburg, Lübeck and Halle (Saale)).

\section{Intervention and control}

The STADPLAN study uses a complex intervention which was established in accordance with the UK Medical Research Council's (MRC) guidance for developing and evaluating complex interventions [31]. Respecting Choices $^{\bullet}$ was implemented in the United States since 1990 [32] and is conceptually based on the ethical principles of informed consent, best interest and shared decision making $[17,33]$. The intervention will be conducted on two levels: (i) the home care service and (ii) the patient level (see Table 1).

\section{Intervention group}

In a 2-days workshop, key nurses from the respective home care services will receive ACP training and be prepared for their role as facilitator (short German version: "BEVA"). This workshop will provide an introduction to $\mathrm{ACP}$ and inform about the possibilities for ADs. Further, BEVAs will train counselling conversations using the conversation guide developed in the STADPLAN study. Finally, conversation experiences and problems, as well as coping strategies will be discussed.

On the patient level, the intervention will include two components which consist of (i) a formal ACP counselling provided by the BEVA and (ii) a written information brochure. The first component, the ACP counselling, is divided into two counselling meetings at the patient's home. The first conversation lasts about $30 \mathrm{~min}$ and follows the developed and pre-tested guideline (Table 1). The written information brochure will be delivered and explained during this first conversation. In a structured approach, this brochure encourages the discussion of health care preferences and wishes regarding future treatment in case a person cannot state his or her opinion anymore. It further includes a glossary of medical and legal terms as well as contact information on local consultancies. The second conversation is also based on a semi-structured guideline and lasts about $60 \mathrm{~min}$. The patient's proxy decision maker or another person of trust, if available, will be invited to take part. 
Table 1 Intervention elements of the STADPLAN study

\begin{tabular}{|c|c|}
\hline Intervention group & Control group (optimised usual care) \\
\hline \multicolumn{2}{|l|}{ Home care service level } \\
\hline $\begin{array}{l}\text { 2-day training for participating nurses } \\
\text { Divided into } 7 \text { modules: } \\
\text { M1: Introduction of the STADPLAN study } \\
\text { M2: Introduction of the topic ACP } \\
\text { M3: Practical exercise of the counselling conversations, extensive practise of the guided } \\
\text { conversations with partners using different health situations/cases } \\
\text { M4: Facilitator's tasks and schedule in the course of the study } \\
\text { M5: Reflexion on conversation experiences } \\
\text { M6: Special practical training of difficult conversational situations, refresher of knowledge } \\
\text { on ACP } \\
\text { M7: Feedback and closing of the training }\end{array}$ & - \\
\hline \multicolumn{2}{|l|}{ Patient level } \\
\hline $\begin{array}{l}\text { ACP counselling (divided into } 2 \text { parts) } \\
\text { Part 1: Information on the project, ACP, aim of the conversations, information on the } \\
\text { tasks and features of the surrogate/ representative, information on the written living will, } \\
\text { introduction of the written information brochure, preparation of the next conversation: } \\
\text { topic and goal, presence of a representative, } \\
\text { Part 2: Repeating information on project, ACP and aim of the conversation, introduction } \\
\text { of the following topics: attitudes, preferences and values of the participant, reflection on } \\
\text { the use of the additional written information and integration of notes, clarification: } \\
\text { further conversations requested? }\end{array}$ & - \\
\hline $\begin{array}{l}\text { Written information on ACP: } \\
\text { Information brochure of about } 60 \text { pages containing: } \\
\text { - Introduction to ACP, surrogate decision making and advance directive documents } \\
\text { - Presentation of critical health scenarios along with incapacity } \\
\text { - Glossary of medical and legal terms, contact information on local consultancies }\end{array}$ & $\begin{array}{l}\text { Written information on ACP: } \\
\text { Brochure of about } 15 \text { pages containing: } \\
\text { - Introduction to ACP, surrogate decision making and } \\
\text { advance directive documents (condensed) } \\
\text { - Presentation of critical health scenarios along with } \\
\text { incapacity (condensed) } \\
\text { - Glossary of medical and legal terms, contact information } \\
\text { on local consultancies }\end{array}$ \\
\hline
\end{tabular}

$\overline{A C P}$ advance care planning, $B E V A$ trained nurse facilitator

Reasons for discontinuing intervention are withdrawing consent, death, or moving to a nursing home.

The intervention's primary aim is to promote patients' awareness of ACP and their activation with respect to future treatment preferences. It also supports the conversation between patients and their proxy about wishes and treatment aims and motivates to this process to be able to take into account future changes or modifications of the patients' wishes. The completion of AD forms is not part of the intervention.

\section{Control group}

Patients in the control group will receive optimised usual care, i.e., provision of written information on ACP (an abbreviated version of the information brochure) at the beginning of the study.

After completion of the data collection, interested nurses of the home care services in the control group will be offered a 1-day workshop on ACP.

\section{Primary outcome}

The primary outcome is patient activation, assessed by the Patient Activation Measure (PAM-13-D) [34] at 12 months. The PAM-13 is a valid and reliable instrument which measures the degree to which individuals take an active role in managing their own health, the corresponding health care and its consequences, and the extent to which they feel competent to fulfil that role [35]. The German version (PAM-13-D) has shown to be a reliable and valid measure of patient activation [36, 37]. Each item can be answered with one of four possible response options, which range from "disagree strongly" [1] to "agree strongly" [4]. One item (no. 4) has a fifth response option, namely "I do not take medications". Raw scores are added up (range 0-100) with higher scores indicating more participation. The PAM-13-D will be assessed via face-to-face interviews by trained study assistants who are blinded to the group allocation of clusters.

\section{Secondary outcomes}

The secondary outcomes are the proportion of participants with ADs, self-reported health related quality of life (VR-12 with 12 items) [38, 39], anxiety and depression (HADS with 14 items) [40], number of hospitalisations, proportion of participants being institutionalized, mortality, and ACP engagement with four items on readiness to pass the ACP process [41] (Table 2). Data measurement will be conducted at baseline (t0), after 6 months (t1) and after 12 months (t2). Baseline data will 
Table 2 Study outcomes/variables, measurement tools and data collection schedule

\begin{tabular}{|c|c|c|c|c|c|c|}
\hline Outcome/ variable & Measured by & Validated version* & Baseline & $\begin{array}{l}6 \text { months } \\
(\mathrm{t} 1)\end{array}$ & $\begin{array}{l}12 \text { months } \\
\text { (t2) }\end{array}$ & Assessed by \\
\hline $\begin{array}{l}\text { Patient activation (primary } \\
\text { outcome) }\end{array}$ & $\begin{array}{l}\text { Patient activation } \\
\text { Measure (PAM-13) [42] }\end{array}$ & German version [36] & $\checkmark$ & $\checkmark$ & $\checkmark$ & RA - at home visit \\
\hline ACP behaviour & $\begin{array}{l}\text { Patient engagement } \\
\text { survey [41] }\end{array}$ & English version [41] & $\checkmark$ & & $\checkmark$ & RA - at home visit \\
\hline Anxiety and depression & $\begin{array}{l}\text { Hospital anxiety and } \\
\text { depression scale } \\
\text { (HADS) [40] }\end{array}$ & German version [43] & $\checkmark$ & & $\checkmark$ & RA - at home visit \\
\hline $\begin{array}{l}\text { Self-reported, health-related } \\
\text { quality of life }\end{array}$ & $\begin{array}{l}\text { Veterans Health } \\
\text { Administration } \\
(\text { VR-12) }[38,39]\end{array}$ & German version [44] & $\checkmark$ & & $\checkmark$ & RA - at home visit \\
\hline $\begin{array}{l}\text { Deaths, hospitalization, } \\
\text { institutionalisation }\end{array}$ & Own questions & n.a. & $\checkmark$ & $\checkmark$ & $\checkmark$ & $\begin{array}{l}\text { RA - at home care service \& } \\
\text { home visit }\end{array}$ \\
\hline Proxy/Family involvement** & $\begin{array}{l}\text { Audit of ACP } \\
\text { discussion }\end{array}$ & n.a. & $\checkmark$ & & & Nurse facilitator \\
\hline $\begin{array}{l}\text { Sociodemographic \& clinical data, } \\
\text { hearing capacity by } \\
\text { RAI-NH [45] \& vision }\end{array}$ & Own questions & n.a. & $\checkmark$ & & & $\begin{array}{l}\text { RA- at home care service \& } \\
\text { home visit }\end{array}$ \\
\hline GPs involvement & Own questions & n.a. & $\checkmark$ & $\checkmark$ & $\checkmark$ & \\
\hline $\begin{array}{l}\text { Physician visits, formal \& informal } \\
\text { care }\end{array}$ & Own questions & n.a. & $\checkmark$ & & $\checkmark$ & RA - at home visit \\
\hline Healthcare preferences & Hypothetical scenarios & $\begin{array}{l}\text { Adapted German } \\
\text { version }[46]^{* * *}\end{array}$ & $\checkmark$ & & $\checkmark$ & RA - at home visit \\
\hline
\end{tabular}

*all instruments were pretested in a German version in the pilot study; ${ }^{* * i n t e r v e n t i o n ~ g r o u p ~ o n l y ; ~}{ }^{* *}$ adapted version of the Life-Support Preferences Questionnaires and Emanuel Medical Directive, which will be validated in the STADPLAN study within a limited subgroup ( $n=120$ ); RA Research assistant, RAI-NH Resident Assessment Instrument for Nursing Homes

include age, sex, family situation, amount of health care services used, selected comorbidities, hearing capacity, vision, mobility, and functional status. Most of these data will be assessed in face-to-face interviews with the patients at their homes. Data routinely documented by the respective home care services will be collected during visits at the home care service.

\section{Process evaluation}

The comprehensive process evaluation follows the UK MRC guidance for the process evaluation of complex interventions [47], aiming to identify the context of the intervention delivery, assess implementation and intervention fidelity, identify mechanisms of impact and interpret outcomes in the light of these identified processes. Thus, observed effects can be interpreted in the light of how the intervention actually worked. Methods comprised are qualitative interviews, focus groups, written questionnaires, and extensive documentation of the ongoing research process, based on a prespecified logic model. A more comprehensive protocol for the process evaluation will be submitted later.

\section{Health economic evaluation}

In consideration of O'Hanlons' framework on economic evaluations of ACP [48], the objective of the health economic evaluation is to estimate implementation and intervention costs during the study period. Cluster adjustment will be performed. Further, cost implications of the ACP intervention will be explored.

The estimation of (i) implementation und intervention costs will be performed from the perspective of the home care services (on organizational level) as well as the German social insurance system (on patient level). Cost implications of the intervention (ii) during the 12month follow-up, in particular inpatient care costs (hospital as well as short-term nursing home), expenses for rehabilitation services and medical devices, will be determined from the perspective of the German social insurance system (on patient level). Cost implications of the intervention, which (iii) could be expected in following years and therewith after the end of our study will be explored by using hypothetic scenarios (on patient level). The scenarios were developed according to international literature on ACP [48-51] and pre-tested during the pilot phase prior the STADPLAN study.

For (i) and (ii), costs for implementation- and intervention-related components will be collected during the study. In a first step, resource use associated with ACP implementation and intervention (e.g. ACP facilitators, qualified nurses, time and material) as well as related health care resource use will be assessed during the study. In a second step, resource use will be multiplied by unit costs. 
The scenarios, which are used for the calculation of point (iii), describe the goals of care chosen by a random subgroup of 120 study participants on cluster level at baseline and at the end of the study for various hypothetic health events. These goals of care will be transformed into costs in three steps: first, we will identify the healthcare resources required to treat the hypothetic health event; second, the amount of resources has to be determined and third, each resource will be multiplied by unit costs. The difference in treatment costs resulting of the decision made at baseline and at the end of the study will be compared between the intervention and the control group.

\section{Sample size}

To detect an effect size of 0.35 (Cohens d), which corresponds to a medium effect, with respect to the primary endpoint after 12 months between the intervention and the control group with $90 \%$ power $(\beta=0.10)$ using a two-sided significance level of $5 \%(\alpha=0.05)$ based on the t-test, a non-cluster study setting would require a total of 173 patients per group. Taking cluster sampling into account [52], we used an intra-cluster correlation coefficient (ICC) of 0.05 in accordance with a study on the effectiveness of ACP in the Netherlands of Korfage et al. [20]. Assuming an average cluster size of 30 participants per home care service, the design factor is 2.45 and 15 clusters are required per group. Estimating that two home care services might drop out [21], 32 clusters with a total of 960 participants will be included in the study.

\section{Data analysis}

Data analyses will be conducted by a blinded biometrician $(\mathrm{BH})$, who does not know, which group is intervention or control, following Good Clinical Practice (GCP) standards. All analyses will be cluster-adjusted and follow the intention-to-treat principle.

Baseline characteristics will be displayed descriptively. The primary outcome (PAM-13-D) will be compared between intervention and control group using a mixed model ( $\alpha=0.05$, two-sided) and adjusted for fixed (baseline values including initial value of PAM-13-D) and random (cluster) effects. For patients who early terminated the study, last observations (information at the last point of measurement) will be carried forward (LOCF imputation). For sensitivity, the same analysis will be performed as complete case analysis without LOCF. Furthermore, a more detailed analysis comparing the longitudinal course of the primary outcome in the interim time points after 6 and 12 months without imputation will be investigated using a mixed model with the intervention and initial PAM-13-D values as fixed effects, clusters as a random effect, and using covariance patterns to adjust for repeated measurement.
Mixed models will also be used for all secondary endpoints, taking into account cluster effects or repeated measurements. Survival analyses will be conducted using stratified Kaplan-Meier curves and Cox regression. Subgroup analyses will be conducted stratified by age and sex.

Economic analyses on patient level will include individual total costs over 12 months. Differences between intervention and control group will be estimated using Gamma regression, again accounting for cluster effects. Adjustment is planned for prematurely dropped out. On organizational level (implementation and intervention costs from the perspective of home care services) descriptive analyses are will be performed.

For the process evaluation, qualitative data (interviews and focus groups) will be summarised and narratively described [53] supported by MAXQDA. Further, quantitative data (questionnaires with closed-and open-ended questions) will be analysed using descriptive statistics.

\section{Data management}

All data will be collected by blinded study assistants at each study site using standardised Case Report Forms (CRFs). Afterwards, the CRFs will be digitalised using the data management system secuTrial ${ }^{\circ}$. Extensive plausibility checks and data validation will be conducted by the trained researcher (BW), who has also developed and proven the database following GCP rules. Data of drop outs will be analysed until drop out date (intention-to-treat), except the withdrawing consent goes along with the wish to delete all data. All personalised contact data and key lists remain under lock at the respective study site so that confidentiality will be preserved.

\section{Trial status}

Home care service recruitment started in April 2019 and patient recruitment was completed in January 2020. The baseline was also completed in January 2020 and the 12month follow-up will accordingly be completed in January 2021. Analyses will be completed in March 2021.

\section{Patient and public involvement}

Patients and public were not involved in the definition of the research questions or outcome measures. However, patients and their relatives were involved in the pilot study, as feasibility and acceptability were tested also from their point of view. Additionally, one of the largest organisations of relatives of care dependent persons in Germany supports the STADPLAN study and is represented on the advisory board representing medical, statistical, medical law, ethics and patient advocacy expertise. Furthermore, pilot study results were presented 
and discussed on international conferences before finalizing the concept for the main study.

\section{Discussion}

The STADPLAN study takes place given the fact that most of the recent international publications on ACP interventions were conducted or are actually running in the primary care setting [54-56] or in the hospital setting [57-59] after a time of investigating ACP mainly in the nursing home setting [60]. However, more evidence on the effectiveness of ACP-interventions in different settings is needed, also taking into account the structures of respective healthcare systems. STADPLAN is the first study in Germany that assesses an adapted ACP intervention in the home care service setting using trained nurses as facilitators. Furthermore, it is the first study internationally that focuses on the effectiveness and costs of ACP in community-dwelling older persons. Results will help to improve understanding and communicating patients' will regarding future medical treatment and care, and thereby contribute to patients' autonomy at the end of life.

\section{Limitations}

As the ACP intervention will be provided only in German and only to patients being cognitively able to follow the intervention, patients with inadequate German language skills or with dementia will be excluded. As the study participation will take at least $40 \mathrm{~h}$ per home care service at the intervention group as well as the target population is a vulnerable older group, it cannot be excluded, that higher drop-out rates will occur. Drop-outs might cause a potential bias. We plan analyses using imputation by LOCF without multiple imputation, and additionally an analysis of the complete time course to discuss a possible bias of the result form drop-outs.

\section{Strengths}

The study has several strengths. We will assess the effectiveness of ACP for the first time in the home care setting. Further, the cluster-randomised design will provide a high level of evidence on the question whether patient activation may be increased by our intervention. Apart from the experimental interventions, control and intervention group clusters will be treated equally in order to prevent performance bias. As successfully performed in previous studies $[29,61,62]$, we will spend a lot of effort to avoid cluster drop-outs (e.g. by regularly telephone calls with the BEVAs and various offers for support), which could lead to cluster imbalance and pronounced lost to follow up. Additionally, the study duration of 12 months provides the possibility to assess long-term effects.
A further strength of our study is the extensive process evaluation since changing attitudes or behaviours in complex interventions pose the challenge of determining how contextual components of participants and home care services interact and influence the intended outcome.

\section{Abbreviations}

ACP: Advance Care Planning; AD: Advance directive; BEVAs: Trained nurse facilitator; CRF: Case report form; DSS: Dementia Screening Scale; GP: General practitioner; HADS: Hospital Anxiety and Depression Scale; ICC: Intra-cluster correlation coefficient; LOCF: Last observation carried forward; $\mathrm{NH}$ : Nursing home; PAM: Patient Activation Measure; RA: Research assistant;

STADPLAN: Study on advanced care planning in care dependent community-dwelling older persons

\section{Acknowledgments}

We would like to thank all members of the advisory board who took part in telephone conferences and provided helpful advices regarding the used measurement instruments and practical aspects for conducting the STADPLAN intervention (especially Professor Jürgen in der Schmitten, Professor Michael Freitag, Professor Jürgen M. Bauer and Brigitte Bührlen). We also thank Dr. Kathrin Jobski for helping with the manuscript draft as well as the four home care services and their patients who participated in the pilot study.

\section{Trial sponsor}

University of Oldenburg, Prof. Dr. Falk Hoffmann

\section{Authors' contributions}

$\mathrm{FH}, \mathrm{SK}, \mathrm{GM}$ and JK-N conceived the study. FH is the head of the coordinating centre. $\mathrm{BH}, \mathrm{JK}-\mathrm{N}$ and $\mathrm{FH}$ designed the statistical analysis plan for the study. JK-N and YC designed the economic evaluation. SK designed the process evaluation plan. $H L, A B, A ̈ K$ and $G M$ developed the intervention. BW planned the data management, developed the database and pilot-tested it. RS, FH, KS and $\ddot{A K}$ drafted the manuscript. All authors read, provided important revisions and approved the final version of the manuscript.

\section{Funding}

The study is funded by the German Federal Ministry of Education and Research (BMBF grant 01GL1707A-D). The funding institution will not interfere in any part of the study.

\section{Availability of data and materials}

Not applicable.

\section{Ethics approval and consent to participate}

The STADPLAN study was approved by the Ethics Committees of the Medical Faculties of the Universities of the Martin Luther University HalleWittenberg (no. 2019-045), the Carl von Ossietzky University Oldenburg (no. 2019-024), and the University of Lübeck, Germany in a joint approval. In the case of important protocol modifications, the above mentioned Ethics Committees as well as the funding institution will be informed immediately. Written informed consent was obtained from each participating patient before the start of the trial.

Although a cognitive decline was an exclusion criterion in our study (see the "In- and exclusion criteria for patients" subheading), we additionally provided an information- and ethical consent for participation sheet for legal

guardians or representatives.

\section{Consent for publication}

Not applicable.

\section{Competing interests}

The authors declare that they have no competing interests.

\section{Author details}

${ }^{1}$ Department of Health Services Research, Faculty of Medicine and Health Sciences, Carl von Ossietzky University Oldenburg, Oldenburg, Germany. ${ }^{2}$ Institute for Social Medicine and Epidemiology, Nursing Research Unit, 
University of Lübeck, Lübeck, Germany. ${ }^{3}$ Medical Faculty, Institute for Healthand Nursing Science, Martin Luther University Halle-Wittenberg, Halle, Germany. ${ }^{4}$ Center for Health Economics and Health Services Research, Schumpeter School of Business and Economics, University of Wuppertal, Wuppertal, Germany. ${ }^{5}$ mediStatistica, Neuenrade, Germany. ${ }^{6}$ Institute for General Practice, Hannover Medical School, Hannover, Germany.

\section{Received: 11 November 2019 Accepted: 25 March 2020} Published online: 17 April 2020

\section{References}

1. World Health Organization. Active Ageing. A policy framework. Geneva: World Health Organization; 2002. Available from: https://scholar.google.co. th/scholar?hl=th\&q=active+ageing\&btnG=\#1.

2. World Health Organization. World report on ageing and health [internet]. Geneva: World Health Organization; 2015. Available from: https://apps.who. int/iris/handle/10665/186463.

3. Luppa M, Riedel-Heller SG, Luck T, Wiese B, van den Bussche H, Haller $F$, et al. Age-related predictors of institutionalization: results of the German study on ageing, cognition and dementia in primary care patients (AgeCoDe). Soc Psychiatry Psychiatr Epidemiol. 2012;47(2):263-70.

4. Schulze J, van den Bussche H, Kaduszkiewicz H, Koller D, Hoffmann F. Institutionalization in incident dementia cases in comparison to age- and sex- matched controls: a 5-year follow-up from Germany. Soc Psychiatry Psychiatr Epidemiol. 2015;50(1):143-51.

5. Ronald LA, McGregor MJ, McGrail KM, Tate RB, Broemling A-M. Hospitalization rates of nursing home residents and community-dwelling seniors in British Columbia. Can J Aging. 2008;27(1):109-15.

6. Koller D, Kaduszkiewicz H, Van Den Bussche H, Eisele M, Wiese B, Glaeske G, et al. Survival in patients with incident dementia compared with a control group: a five-year follow-up. Int Psychogeriatrics. 2012;24(9):1522-30.

7. Statistisches Bundesamt Destatis. Pflegestatistik 2017- Pflege im Rahmen der Pflegeversicherung, vol. 49; 2018. Available from: https://www.destatis.de/ DE/Themen/Gesellschaft-Umwelt/Gesundheit/Pflege/Publikationen/ Downloads-Pflege/laender-pflegebeduerftige-5224002179004.pdf?_blob= publicationFile.

8. Rothgang $H$, Kalwitzki T, Müller R, Runte R, Unger R. BARMER GEK Pflegereport 2015 [Internet]. St. Augustin: Asgard; 2015. Available from: https://www.barmer.de/blob/36042/73f4ded2ea20652834aeedbb7c2bc16a/ data/pdf-barmer-gek-pflegereport-2015.pdf.

9. Statistisches Bundesamt (DESTATIS). Pflegebedürftige im Dezember 2015. 2017 [cited 2019 Mar 2]. p. 1. Available from: https://www.destatis.de/DE/ PresseService/Presse/Pressemitteilungen/2017/01/PD17_017_224pdf.pdf; jsessionid=015B47E674E9BCC5CDFE27FE1631818C.InternetLive2?_blob= publicationFile.

10. Austin CA, Mohottige D, Sudore RL, Smith AK, Hanson LC. Tools to promote shared decision making in serious illness: a systematic review. JAMA Intern Med. 2015;175(7):1213-21.

11. Glaudemans JJ, Moll van Charante EP, Willems DL. Advance care planning in primary care, only for severely ill patients? A structured review. Fam Pract. 2015;32(1):16-26.

12. Evans N, Bausewein C, Meñaca A, Andrew EWW, Higginson IJ, Harding R, et al. A critical review of advance directives in Germany: attitudes, use and healthcare professionals' compliance. Patient Educ Couns. 2012;87(3):277-88.

13. Der Schmitten Jl, Lex K, Mellert C, RothÄrmel S, Wegscheider K, Marckmann G. Patientenverfügungsprogramm: Implementierung in Senioreneinrichtungen. Dtsch Arztebl Int. 2014;111(4):50-7.

14. Sommer S, Marckmann G, Pentzek M, Wegscheider K, Abholz H-H, in der Schmitten J. Advance directives in nursing homes: prevalence, validity, significance, and nursing staff adherence. Dtsch Ärzteblatt Int. 2012;109(37): 577-83.

15. Combes S, Nicholson CJ, Gillett K, Norton C. Implementing advance care planning with community-dwelling frail elders requires a system-wide approach: an integrative review applying a behaviour change model. Palliat Med. 2019;33(7):743-56.

16. Aasmul I, Husebo BS, Sampson EL, Flo E. Advance care planning in nursing homes - improving the communication among patient, family, and staff: results from a cluster randomized controlled trial (COSMOS). Front Psychol. $2018 ; 9: 2284$.
17. Detering KM, Hancock AD, Reade MC, Silvester W. The impact of advance care planning on end of life care in elderly patients: randomised controlled trial. BMJ. 2010;340:C1345.

18. Houben CHM, Spruit MA, Groenen MTJ, Wouters EFM, Janssen DJA. Efficacy of advance care planning: a systematic review and meta-analysis. J Am Med Dir Assoc. 2014;15(7):477-89.

19. Overbeek A, Korfage IJ, Jabbarian LJ, Billekens P, Hammes BJ, Polinder S, et al. Advance care planning in frail older adults: a cluster randomized controlled trial. J Am Geriatr Soc. 2018;66(6):1089-95.

20. Korfage IJ, Rietjens JAC, Overbeek A, Jabbarian LJ, Billekens P, Hammes BJ, et al. A cluster randomized controlled trial on the effects and costs of advance care planning in elderly care: study protocol. BMC Geriatr. 2015; 15(1):87.

21. Dixon J, Matosevic T, Knapp M. The economic evidence for advance care planning: systematic review of evidence. Palliat Med. 2015;29(10):869-84.

22. Klingler C. In der Schmitten J, Marckmann G. does facilitated advance care planning reduce the costs of care near the end of life? Systematic review and ethical considerations. Palliat Med. 2016;30(5):423-33.

23. Craig P, Dieppe P, Macintyre S, Michie S, Nazareth I, Petticrew M, et al. Developing and evaluating complex interventions: the new Medical Research Council quidance. BMJ. 2008:337:a1655.

24. Hammes BJ, Rooney BL. Death and end-of-life planning in one Midwestern community. Arch Intern Med. 1998;158(4):383 [cited 2019 Sep 5] Available from: http://www.ncbi.nlm.nih.gov/pubmed/9487236.

25. Michie S, Atkins L, West R. The Behaviour Change Wheel: a guide to designing interventions. 1st ed. London: Silverback Publishing. p. 329.

26. Köhler L, Weyerer $S$, Schäufele M. Proxy screening tools improve the recognition of dementia in old-age homes: results of a validation study. Age Ageing. 2007 Sep;36(5):549-54.

27. Statistisches Bundesamt. Pflegestatistik 2011. Pflege Im Rahmen Der Pflegeversicherung: Kreisvergleich. Wiesbaden: Statistisches Bundesamt; 2013.

28. Hoffmann F, Boeschen D, Dörks M, Herget-Rosenthal S, Petersen J, Schmiemann G. Renal Insufficiency and Medication in Nursing Home Residents. Dtsch Aerzteblatt Online. 2016[cited 2019 Jul 26]; Available from: https://www.aerzteblatt.de/10.3238/arztebl.2016.0092.

29. Köpke S, Mühlhauser I, Gerlach A, Haut A, Haastert B, Möhler R, et al. Effect of a guideline-based multicomponent intervention on use of physical restraints in nursing homes: a randomized controlled trial. JAMA. 2012; 307(20):2177-84.

30. Verbeek H, Meyer G, Leino-Kilpi H, Zabalegui A, Hallberg IR, Saks K, et al. A European study investigating patterns of transition from home care towards institutional dementia care: the protocol of a RightTimePlaceCare study. BMC Public Health. 2012;12:68.

31. Craig P, Dieppe P, Macintyre S, Michie S, Nazareth I, Petticrew M. Developing and evaluating complex interventions: an introduction to the new Medical Research Council guidance. In: Evidence-based public health: effectiveness and efficiency; 2010.

32. Respecting Choices - Person-Centered Care. History of respecting Respecting Choices. [cited 2019 Sep 6]. Available from: https:// respectingchoices.org/about-us/history-of-respecting-choices/.

33. Hammes BJ, Briggs L. Das »Respecting Choices« Advance-Care-PlanningProgramm in den USA: ein nachgewiesener Erfolg. In: Coors M, Jox RJ, in der Schmitten J, editors. Advance Care Planning Von Der Patientenverfügung Zur Gesundheitlichen Vorausplanung. W. Kohlhammer GmbH, Stuttgart; 2015. p. 181-96.

34. Hibbard JH, Mahoney ER, Stockard J, Tusler M. Development and testing of a short form of the patient activation measure. Health Serv Res. 2005;40(6 I): 1918-30.

35. Hibbard JH, Mahoney E. Toward a theory of patient and consumer activation. Patient Educ Couns. 2010;78(3):377-81 [cited 2019 Apr 2] Available from: https://inkinghub.elsevier.com/retrieve/pii/S0738399110000170.

36. Zill JM, Dwinger S, Kriston L, Rohenkohl A, Härter M, Dirmaier J. Psychometric evaluation of the German version of the patient activation measure (PAM13). BMC Public Health. 2013;13:1027.

37. Brenk-Franz K, Hibbard JH, Herrmann WJ, Freund T, Szecsenyi J, Djalali S, et al. Validation of the German Version of the Patient Activation Measure 13 (PAM13-D) in an International Multicentre Study of Primary Care Patients. Janda M, editor. PLoS One. 2013;8(9):e74786

38. Kazis LE, Lee A, Spiro A, Rogers W, Ren XS, Miller DR, et al. Measurement comparisons of the medical outcomes study and veterans SF-36 health survey. Health Care Financ Rev. 2004;25(4):43-58. 
39. Kazis LE, Miller DR, Skinner KM, Lee A, Ren XS, J a C, et al. Patient-reported measures of health: the veterans health study. J Ambul Care Manage. 2004; 27(1):70-83.

40. Johnston M, Pollard B, Hennessey P. Construct validation of the hospital anxiety and depression scale with clinical populations. J Psychosom Res. 2000;48(6):579-84

41. Sudore RL, Heyland DK, Barnes DE, Howard M, Fassbender K, Robinson CA, et al. Measuring advance care planning: optimizing the advance care planning engagement survey. J Pain Symptom Manage. 2017;53(4):669-81 e8.

42. Hibbard JH, Stockard J, Mahoney ER, Tusler M. Development of the patient activation measure (PAM): conceptualizing and measuring activation in patients and consumers. Health Serv Res. 2004;39(4 Pt 1):1005-26.

43. Herrmann C, Scholz KH, Kreuzer H. Psychologic screening of patients of a cardiologic acute care clinic with the German version of the hospital anxiety and depression scale. Psychother Psychosom Med Psychol. 1991; 41(2):83-92.

44. Ware J, Kosinski M, Keller SD. A 12-item short-form health survey: construction of scales and preliminary tests of reliability and validity. Med Care. 1996;34(3):220-33.

45. Mukamel DB, Ladd H, Caprio T, Temkin-Greener H. Prototype end-of-life quality measures based on MDS 3 data. Med Care. 2016;54(11):1024-32.

46. Emanuel $L L$, Emanuel EJ. The medical directive. A new comprehensive advance care document. JAMA. 1989;261(22):3288-93.

47. Moore GF, Audrey S, Barker M, Bond L, Bonell C, Hardeman W, et al. Process evaluation of complex interventions: Medical Research Council guidance. BMJ. 2015;350:h1258.

48. O'Hanlon CE, Walling AM, Okeke E, Stevenson S, Wenger NS. A framework to guide economic analysis of advance care planning. J Palliat Med. 2018; 21(10):1480-5.

49. Schwartz CE, Merriman MP, Reed GW, Hammes BJ. Measuring patient treatment preferences in end-of-life care research: applications for advance care planning interventions and response shift research. J Palliat Med. 2004; 7(2):233-45.

50. Coppola KM, Bookwala J, Ditto PH, Lockhart LK, Danks JH, Smucker WD. Elderly adults' preferences for life-sustaining treatments: the role of impairment, prognosis, and pain. Death Stud. 1999;23(7):617-34 [cited 2019 Jul 26] Available from: http://www.tandfonline.com/doi/abs/10.1080/074811 899200803.

51. Froman RD, Owen SV. Validation of the Spanish Life Support Preference Questionnaire (LSPQ). J Nurs Scholarsh an Off Publ Sigma Theta Tau Int Honor Soc Nurs. 2003;35(1):33-6.

52. Gao F, Earnest A, Matchar DB, Campbell MJ, Machin D. Sample size calculations for the design of cluster randomized trials: a summary of methodology. Contemp Clin Trials. 2015;42:41-50.

53. Mayring P. Qualitative Inhaltsanalyse : Grundlagen und Techniken. 11th ed. Weinheim: Beltz; 2010

54. Walling AM, Sudore RL, Bell D, Tseng C-H, Ritchie C, Hays RD, et al. Population-based pragmatic trial of advance care planning in primary Care in the University of California health system. J Palliat Med. 2019;22(S1):7281.

55. Totten AM, Fagnan LJ, Dorr D, Michaels LC, Izumi SS, Combe A, et al. Protocol for a cluster randomized trial comparing team-based to clinicianfocused implementation of advance care planning in primary care. J Palliat Med. 2019;22(S1):82-9.

56. Nassikas NJ, Baird GL, Duffy CM. Improving advance care planning in a resident primary care clinic. Am J Hosp Palliat Care. 2019;2: 1049909119872757

57. Hamayoshi M, Goto S, Matsuoka C, Kono A, Miwa K, Tanizawa K, et al. Effects of an advance care planning educational programme intervention on the end-of-life care attitudes of multidisciplinary practitioners at an acute hospital: a pre- and post-study. Palliat Med. 2019;33(9):269216319860707.

58. Yip K, Wong T, Alhamid S, Nadkarni N, Tan C, Pang A, et al. Integrating advance care planning as part of comprehensive geriatric assessment for hospitalised frail elderly patients: findings of a cross-sectional study. Singapore Med J. 2019; [cited 2019 Sep 10]; Available from: http://www.smj. org.sg/sites/default/files/OA-2018-041-epub.pdf.

59. Gagliardi L, Morassaei S. Optimizing the role of social workers in advance care planning within an academic hospital: an educational intervention program. Soc Work Health Care. 2019;58(8):796-806.
60. Martin RS, Hayes B, Gregorevic K, Lim WK. The effects of advance care planning interventions on nursing home residents: a systematic review. J Am Med Dir Assoc. 2016;17(4):284-93.

61. Abraham J, Kupfer R, Behncke A, Berger-Höger B, Icks A, Haastert B, et al. Implementation of a multicomponent intervention to prevent physical restraints in nursing homes (IMPRINT): a pragmatic cluster randomized controlled trial. Int J Nurs Stud. 2019;96:27-34.

62. Richter C, Berg A, Langner H, Meyer G, Köpke S, Balzer K, et al. Effect of person-centred care on antipsychotic drug use in nursing homes (EPCentCare): a cluster-randomised controlled trial. Age Ageing. 2019;48(3): $419-25$

\section{Publisher's Note}

Springer Nature remains neutral with regard to jurisdictional claims in published maps and institutional affiliations.
Ready to submit your research? Choose BMC and benefit from:

- fast, convenient online submission

- thorough peer review by experienced researchers in your field

- rapid publication on acceptance

- support for research data, including large and complex data types

- gold Open Access which fosters wider collaboration and increased citations

- maximum visibility for your research: over $100 \mathrm{M}$ website views per year

At BMC, research is always in progress.

Learn more biomedcentral.com/submissions 